\title{
LA CRISIS DE ChIAPAS: NEGOCIACIONES, DEMOCRACIA Y GOBERNABILIDAD
}

\author{
Tania Carrasco \\ Raúl Benítez Manaut \\ Armando Rodríguez Luna
}

Resumen: El conflicto en Chiapas se encuentra en una especie de impasse porque el gobierno mexicano y el EZLN han desarrollado estrategias diferentes. El gobierno ha apostado a transformaciones legislativas evitando llegar a la negociación política; el EZLN no desea reducir sus demandas de transformar política, económica e ideológicamente al Estado y transformarse de una fuerza militar en una política. Ambas estrategias dejan de lado la negociación y ponen en cuestionamiento el proceso democrático y la gobernabilidad en México.

Palabras clave: Chiapas, democracia, EZLN, derechos indígenas, negociación, marginación, seguridad nacional.

Enviado a dictamen: 09 de junio de 2007.

Aprobación: 02 de septiembre de 2007.

Tania Carrasco, consultora del Banco Mundial.

Raúl Benítez Manaut, investigador del Centro de Investigaciones sobre América del Norte, UNAM.

Armando Rodríguez Luna, profesor-investigador de la Universidad del Mar, Campus Huatulco.
Abstract: The conflict in Chiapas has entered into an impasse because the Mexican government and the EZLN have developed different strategies. On one hand, the Mexican government has made legal transformations avoiding political negotiation. On the other hand, the EZLN has decided not to reduce his demands of Mexico's political, economical and ideological transformation and transform in self form military force into a political one. Both strategies leave behind negotiation and foremost put in question the democratic process and governance in Mexico.

Key words: Chiapas, democracy, EZLN, indigenous rights, negotiation, marginalization, national security.

\section{Chiapas: un eslabón débil de la democracia mexicana}

$\mathrm{E}$ Estado mexicano mostró notable incapacidad durante el siglo XX para lograr encontrar estrategias que permitieran resolver el tema de la exclusión política, pobreza y marginación de los pueblos indígenas. De acuerdo con el censo del año 2000, en México existían 6.7 millones de personas hablantes de lenguaindígena sobre un total de 98 millones de habitantes. En Chiapas, la población indígena representa aproximadamente 30\% del total (INEGI, 2000; INI-CONAPO). ${ }^{l}$ El Estado y sus instituciones son prácticamenteinexistentes, predominando modalidades autoritarias y tradicionales de control político. 
En la Constitución, a partir del año 2001, con la promulgación de la Ley de Derechos y Cultura Indígena, ${ }^{2}$ está plasmada la igualdad jurídica de la población y el reconocimiento de los derechos culturales y políticos de las comunidades indígenas. No obstante, el Estado no ha encontrado los mecanismos para que estos derechos sean efectivos. Es decir, prevalecen la desigualdad y las injusticias en la vida cotidiana de las comunidades y en las relaciones políticas entre el gobierno federal, el estatal y los municipales vis a vis las comunidades indígenas. En otras palabras, el Estado ha sido incapaz de imponer el estado de derecho. ${ }^{3}$ El surgimiento del Ejército Zapatista de Liberación Nacional (EZLN) como grupo armado, en 1994, con sustento en un sector de la población indígena, generó dos dilemas: al proceso de democratización del país y a la seguridad nacional. Antes de 1994, no se había incorporado el tema de los indígenas como actores políticos con derechos al proceso de democratización. El desafío a la seguridad proviene del hecho de que Chiapas es un estado considerado estratégico por contar con $46 \%$ de la producción de electricidad nacional, 23\% de gas licuado y $40 \%$ de la producción nacional de azufre (Álvarez, 2003: 75). Además de ser el estado que colinda con el altiplano guatemalteco.

El primero de enero de 1994 apareció un desafío de orden militar. No obstante, iniciadas las conversaciones y los contactos entre los representantes del gobierno y la dirigencia del EZLN, el 12 de enero de 1994, se volvió fundamentalmente un conflicto de carácter político, que ponía en cuestión el proceso de democratización. De esa manera, al estar el país viviendo una transición democrática, la rebelión inmediatamente impactó en los partidos políticos nacionales y tuvo influencia en el proceso electoral que se vivía en ese entonces. Las negociaciones en Chiapas fueron importantes en las elecciones intermedias de $1997 \mathrm{y}$ en las presidenciales del año 2000. Hacía la elección de 2006 la crisis de Chiapas y el tema indígena quedaron al margen de los debates.

\section{Negociación en punto muerto}

El conflicto armado entre el ejército mexicano y el EZLN sólo duró doce días, en tanto que la probable negociación sobre la paz continúa hasta la fecha. En 13 años no ha podido lograrse una negociación que transforme al EZLN de "actor militar" en estado de guerra en actor político. El Estado mexicano ha recurrido a la negociación política utilizando los cambios en la Constitución y la ley de 2001 para dar solución al conflicto. El EZLN optó por dirigir su estrategia hacia los medios de comunicación, nacionales e internacionales, tratando de obtener mayor apoyo social y legitimidad para su causa.

El EZLN se ha enfrentado al gobierno mexicano de manera indirecta, con tal de evadir la presión que ha ejercido el ejército de forma disuasiva con un intenso despliegue de tropas desde 1994. Trata de mantener su presencia mediante convocatorias de movilización social u organización comunitaria alternativas. El medio para ello ha sido el apoyo de las Organizaciones No Gubernamentales (ONGs) con las que se ha proyectado en los ámbitos nacional e internacional. El dilema del EZLN se encuentra en los ámbitos entre continuar teniendo como epicentro las demandas indígenas no satisfechas con la ley de 2001, o asumir demandas de otros sectores. El dilema del Estado mexicano es encontrar una legislación y formas nuevas de negociación política que logren superar la situación de tensión que se vive en Chiapas, con el EZLN y con las llamadas comunidades autónomas.

La importancia que el gobierno mexicano ha otorgado a la defensa y vigencia del estado de derecho tiene directa relación con la presencia militar en Chiapas y particularmente en las zonas con población predominantemente indígena. Según cifras oficiales de la Secretaría de la Defensa Nacional, en el año 2000, en la VII Región Militar, que abarca los estados de Tabasco y Chiapas, se encontraban 14 mil efectivos, de los cuales 10,500 se encontraban en el estado de Chiapas (Global Exchange, 2000: 112). Hacia el año 2005, según fuentes oficiales, no había más de 20 mil militares en Chiapas (Aguayo, 2007). 
Desde el estallido de la crisis en enero de 1994 hasta el año 2000, la estrategia del gobierno fue el uso de la fuerza de forma constante mediante el despliegue militar disuasivo. Respecto a la solución de las demandas de carácter social y cultural que el levantamiento ha sostenido como eje de su lucha, ha habido poca capacidad del gobierno para promover la inversión privada - excepto hacia el sector turístico-. En el caso de la inversión del gobierno en el sector agrario, campesino e indígena, los recursos financieros gastados en programas sociales no han logrado resolver las condiciones de marginalidad de los pueblos indígenas. Así, la solución política y pacífica del conflicto está en punto muerto o congelada (véase, Benítez, et. al., 2006). El EZLN no reconoce los programas del gobierno como positivos, porque los considera un mecanismo de cooptación política. El gobierno concentra su estrategia sólo en proyectos de modernización a través de inversiones en infraestructura y gasto social con poco impacto en las actividades productivas a largo plazo.

De acuerdo con la información estadística oficial, en Chiapas, los sectores que tienen que ver con el sector primario de la economía (agropecuario y minero) son los que presentan el comportamiento menos dinámico. Mientras, se observa el auge en el área de la construcción en el período 2000-2004. Así, el esfuerzo gubernamental por mejorar la infraestructura en Chiapas no se refleja en el mejoramiento de la calidad de vida de la población del estado.
Por ejemplo, en el año 2000, en el ámbito nacional la cobertura de agua entubada era de $85.2 \%$; en el estado de Chiapas era de 69.3\%; y en las comunidades indígenas, de $65.7 \%$. En el caso de la energía eléctrica, en el país la cobertura era de $95.4 \%$; en Chiapas, de $88.4 \%$; y en las comunidades indígenas, de 78.5\% (Indicadores socioeconómicos, 2002). Por ello, la estrategia del gobierno para desactivar el conflicto a través de la inversión en infraestructura y programas sociales no ha conseguido los resultados esperados. El EZLN no considera que el flujo de dinero resuelva las condiciones de marginalidad.

Ambas partes apostaron a estrategias distintas. El gobierno pensó que con cambios legislativos se solucionaría el problema, principalmente desde la llegada al poder del Partido Acción Nacional (PAN), en diciembre de 2000. El EZLN creía que postulando la transformación macroeconómica del país (para solucionar la pobreza estructural e histórica) iba a lograr arrastrar un caudal de respaldo que presionaría al gobierno. El gobierno fue minimalista, lo jurídico sin solución política no logró desactivar el conflicto. El EZLN fue maximalista, no cuantificó la "correlación de fuerzas", y sostuvo — sin negociar- que la solución estaba en superar la pobreza y la exclusión social, política y cultural de los indígenas, para desactivar su postura bélica. Ambas estrategias dejaron de lado el componente de la negociación: el gobierno no ha cedido y no ha abierto la cuestión jurídica para transformarla en una negociación política, y el EZLN no ha deseado reducir sus demandas y transformarse de una fuerza militar en una política. 
LA CRISIS DE CHIAPAS: NEGOCIACIONES,

La evolución política e ideológica del EZLN se puede resumir de la siguiente manera:

Cuadro 1

Etapas político-ideológicas del EZLN

\begin{tabular}{|c|c|c|c|c|c|}
\hline Etapa 1 & \multicolumn{2}{|c|}{ Etapa 2} & \multicolumn{3}{|c|}{ Etapa 3} \\
\hline 1984-1994 & 1994-1996 & $1996-2000$ & 2001-2003 & 2003-2005 & 2006 \\
\hline $\begin{array}{l}\text { Clandestinidad } \\
\text { en la Selva } \\
\text { Lacandona. } \\
\text { Base de apoyo } \\
\text { en comunidades } \\
\text { indígenas y } \\
\text { campesinas. } \\
\text { Organización } \\
\text { armada foquista } \\
\text { clásica marxista } \\
\text { leninista-maoísta. } \\
\text { Sin relación } \\
\text { con la izquierda } \\
\text { institucional. } \\
\text { Vínculos con } \\
\text { organizaciones } \\
\text { de base de la } \\
\text { Teología de la } \\
\text { Liberación. }\end{array}$ & $\begin{array}{l}\text { Ampliación de } \\
\text { base de apoyo } \\
\text { en el ámbito } \\
\text { nacional. } \\
\text { Incorporación de } \\
\text { las demandas } \\
\text { indígenas en la } \\
\text { agenda nacional, } \\
\text { en el marco del } \\
\text { debate de la } \\
\text { Reforma del } \\
\text { Estado. } \\
\text { Identificación } \\
\text { EZLN-PRD. } \\
\text { Juego político } \\
\text { donde ambos } \\
\text { ganan. } \\
\text { EZLN encuentra } \\
\text { vía política en el } \\
\text { sistema político } \\
\text { sin pertenecer } \\
\text { al mismo y el } \\
\text { PRD incorpora } \\
\text { a esa parte de } \\
\text { la izquierda } \\
\text { ganando mayor } \\
\text { legitimidad en } \\
\text { ese sector (de } \\
\text { las minorías). } \\
\text { ipoyo } \\
\text { internacional. }\end{array}$ & $\begin{array}{l}\text { Debate Acuerdos de } \\
\text { San Andrés } \\
\text { Larraínzar } \\
\text { (1996-1997). } \\
\text { Búsqueda de su } \\
\text { cumplimiento por } \\
\text { parte del EZLN. } \\
\text { Proyecto Las } \\
\text { Abejas. } \\
\text { Paramilitarización } \\
\text { como estrategia } \\
\text { estatal de } \\
\text { contención hacia el } \\
\text { EZLN hasta Acteal, } \\
\text { diciembre de 1997. } \\
\text { De 1998 al 2000 } \\
\text { las negociaciones } \\
\text { entre EZLN y } \\
\text { gobierno están en } \\
\text { punto muerto. } \\
\text { Congelamiento y } \\
\text { repliegue del EZLN. } \\
\text { El tema Chiapas } \\
\text { sale de la agenda } \\
\text { política-electoral. } \\
\text { La instancia de } \\
\text { Mediación es la } \\
\text { coNAl. }\end{array}$ & $\begin{array}{l}\text { Caravana } \\
\text { Zapatista } \\
\text { Marzo } 2001 \\
\text { 1,111 repre- } \\
\text { sentantes. Ley } \\
\text { de Derechos } \\
\text { Indígenas. } \\
\text { Proyecto } \\
\text { Caracoles. } \\
\text { Se inicia } \\
\text { proceso de } \\
\text { distensión } \\
\text { por parte de } \\
\text { los gobiernos } \\
\text { federal y } \\
\text { estatal. } \\
\text { Disminuye } \\
\text { la acción } \\
\text { paramilitar al } \\
\text { mínimo. }\end{array}$ & $\begin{array}{l}\text { Aislamiento y } \\
\text { reflexión. Mutación } \\
\text { del EZLN hacia una } \\
\text { fuerza antisistémica } \\
\text { y antiglobalizadora. } \\
\text { Búsqueda de nueva } \\
\text { bases de apoyo. } \\
\text { Distancia creciente } \\
\text { entre EZLN-PRD. }\end{array}$ & $\begin{array}{l}\text { Coyuntura } \\
\text { electoral. } \\
\text { La otra campaña. } \\
\text { Distanciamiento } \\
\text { EZLN-PRD. } \\
\text { Nuevos vínculos } \\
\text { fuera del estado } \\
\text { de Chiapas } \\
\text { buscando liderear } \\
\text { una izquierda } \\
\text { 'nueva'. } \\
\text { Se acerca y avala } \\
\text { movimientos } \\
\text { sociales que } \\
\text { confrontan al } \\
\text { Estado con } \\
\text { movilizaciones en } \\
\text { la calle. }\end{array}$ \\
\hline
\end{tabular}


Cuadro 2. Comparación de las declaraciones de la Selva Lacandona

\begin{tabular}{|c|c|c|}
\hline $\begin{array}{l}\text { Primera Declaración } \\
\text { (Diciembre de 1993) }\end{array}$ & $\begin{array}{l}\text { Segunda Declaración } \\
\text { (junio 1994) }\end{array}$ & $\begin{array}{l}\text { Sexta Declaración } \\
\text { (junio 2005) }\end{array}$ \\
\hline $\begin{array}{l}\text { - Pero nosotros HOY DECIMOS ¡BASTA!, so- } \\
\text { mos los herederos de los verdaderos forjado- } \\
\text { res de nuestra nacionalidad, los desposeídos } \\
\text { somos millones y llamamos a todos nuestros } \\
\text { hermanos a que se sumen a este llamado } \\
\text { como el único camino para no morir de ham- } \\
\text { bre ante la ambición insaciable de una dicta- } \\
\text { dura de más de } 70 \text { años encabezada por una } \\
\text { camarilla de traidores que representan a los } \\
\text { grupos más conservadores y vendepatrias. } \\
\text { Son los mismos que se opusieron a Hidalgo } \\
\text { y a Morelos, los que traicionaron a Vicente } \\
\text { Guerrero, son los mismos que vendieron más } \\
\text { de la mitad de nuestro suelo al extranjero in- } \\
\text { vasor, son los mismos que trajeron un prínci- } \\
\text { pe europeo a gobernarnos, son los mismos } \\
\text { que formaron la dictadura de los científicos } \\
\text { porfiristas, son los mismos que se opusieron } \\
\text { a la Expropiación Petrolera, son los mismos } \\
\text { que masacraron a los trabajadores ferroca- } \\
\text { rrileros en } 1958 \text { y a los estudiantes en 1968, } \\
\text { son los mismos que hoy nos quitan todo, ab- } \\
\text { solutamente todo. }\end{array}$ & 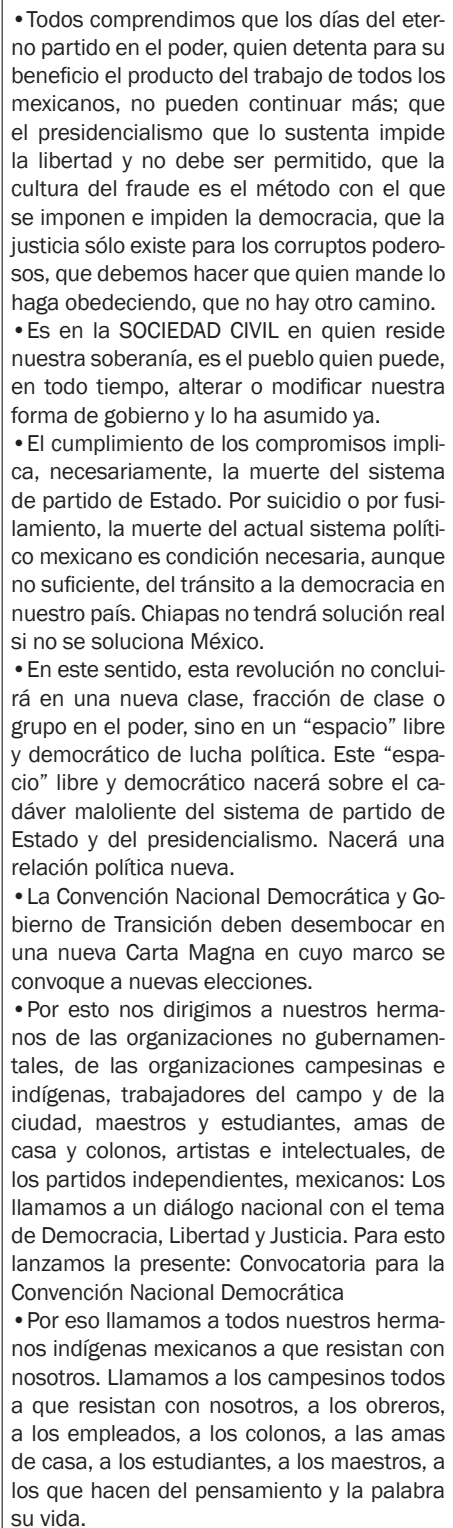 & $\begin{array}{l}\text { - O sea que, como ya explicamos, los go- } \\
\text { bernantes que tenemos están destruyen- } \\
\text { do lo que es nuestra Nación, nuestra Pa- } \\
\text { tria mexicana. Y su trabajo de estos malos } \\
\text { gobernantes no es mirar por el bienestar } \\
\text { del pueblo, sino que sólo están pendientes } \\
\text { del bienestar de los capitalistas. } \\
\text { - Porque resulta que nosotros del EZLN } \\
\text { somos casi todos puros indígenas de acá } \\
\text { de Chiapas, pero no queremos luchar sólo } \\
\text { por su bien de nosotros o sólo por el bien } \\
\text { de los indígenas de Chiapas, o sólo por } \\
\text { los pueblos indios de México, sino que } \\
\text { queremos luchar junto con todos los que } \\
\text { son gente humilde y simple como nosotros } \\
\text { y que tienen gran necesidad y que sufren } \\
\text { la explotación y los robos de los ricos y sus } \\
\text { malos gobiernos aquí en nuestro México y } \\
\text { en otros países del mundo. } \\
\text { - Porque ése es otro problema, y es que } \\
\text { la Constitución ya está toda manoseada y } \\
\text { cambiada. Ya no es la que tenía los dere- } \\
\text { chos y las libertades del pueblo trabajador, } \\
\text { sino que ahora están los derechos y las li- } \\
\text { bertades de los neoliberalistas para tener } \\
\text { sus grandes ganancias. Y los jueces están } \\
\text { para servir a esos neoliberalistas, porque } \\
\text { siempre dan su palabra a favor de ellos, } \\
\text { y a los que no son ricos pues les tocan las } \\
\text { injusticias, las cárceles, los cementerios. } \\
\text { - Vamos a seguir luchando por los pueblos } \\
\text { indios de México, pero ya no sólo por ellos } \\
\text { ni sólo con ellos, sino que por todos los } \\
\text { explotados y desposeídos de México, con } \\
\text { todos ellos y en todo el país. Y cuando de- } \\
\text { cimos que todos los explotados de México } \\
\text { también estamos hablando de los herma- } \\
\text { nos y hermanas que se han tenido que ir } \\
\text { a Estados Unidos a buscar trabajo para } \\
\text { poder sobrevivir. } \\
\text { - También vamos a ir viendo de levantar; } \\
\text { una lucha para demandar que hacemos } \\
\text { una nueva Constitución o sea nuevas le- } \\
\text { yes que tomen en cuenta las demandas } \\
\text { del pueblo mexicano como son: techo, tie- } \\
\text { rra, trabajo, alimento, salud, educación, in- } \\
\text { formación, cultura, independencia, demo- } \\
\text { cracia, justicia, libertad y paz. Una nueva } \\
\text { Constitución que reconozca los derechos } \\
\text { y libertades del pueblo, y defienda al débil } \\
\text { frente al poderoso. }\end{array}$ \\
\hline
\end{tabular}


En consecuencia, el EZLN fue el catalizador (1994-2001) y articulador de algunas de las expresiones de descontento más importantes que provinieron del área rural indígena, en este caso, de Chiapas. Por su parte, el Estado mexicano no ha podido construir mecanismos legales o políticos para relacionarse o negociar con los movimientos emergentes. Es decir, esta debilidad de la actual democracia explica en parte por qué la negociación de paz entre el EZLN y el gobierno se encuentra en punto muerto. Además, el EZLN se ha propuesto 'cobijar' los movimientos sociales contestatarios, lo que ha dificultado su acercamiento hacia el campo de lo institucional', así, ha alejado las posibilidades de negociación con el gobierno. Considerando las declaraciones del EZLN en 'La Otra Campaña' y en la Sexta Declaración de la Selva Lacandona, todo indica que se da una especie de 'regreso a 1994' dado que se retoman muchos elementos de las dos primeras declaraciones de 1994.

\section{Lo jurídico: necesario pero no suficiente}

En 1989, la Organización Internacional del Trabajo (OIT) presentó a todos los países miembros el Convenio 169 sobre Pueblos Indígenas y Tribales. Éste señala las garantías necesarias para el reconocimiento de los pueblos indígenas dentro del orden jurídico de los países, como pueblos con identidades, culturas y usos y costumbres propios (OIT, 1989, ver artículos 7, 9 y 13). México fue el primer país que ratificó dicho Convenio en 1990. En el contexto nacional, a la par de las negociaciones para la firma del Tratado de Libre Comercio de América del Norte (TLCAN), para hacer viable la legislación nacional con el deseo de vincular a México al proceso de globalización y regionalización, se inicia la reforma del Estado, en 1989 (Bailón, 2003). Se hicieron cambios a la Constitución vinculados a la temática indígena, sobre

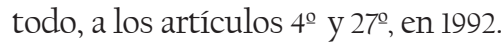

El primero se refiere al reconocimiento de la composición pluricultural que tiene México sustentada en sus pueblos indígenas y que la ley los protegerá y promoverá el desarrollo de sus lenguas, culturas, usos y costumbres, recursos y formas específicas de organización social, garantizando su acceso efectivo a la jurisdicción del Estado (Constitución Política de los Estados Unidos Mexicanos, 2006).

La reforma al artículo 27 puso fin al reparto agrario y sentó las bases para la privatización del ejido; se otorgó derechos a los ejidatarios de enajenar o vender sus parcelas con la idea de liberar la tierra y ponerla a disposición del mercado, a efecto de "capitalizar el campo" e impulsar el desarrollo de la pequeña propiedad. Esta modificación del artículo 27 se produjo por la atomización del ejido y por la escasez estructural de tierras para las nuevas generaciones de campesinos.

Además, hay una crisis de viabilidad ligada a factores tecnológicos, financieros (falta de crédito e inversión), así como el abandono del ejido por parte del Estado por no considerarlo viable (Carrasco y Molnar, 2001). Lo anterior propició el surgimiento de una rebelión política contra estas medidas, cuyas expresiones fueron las tomas de tierras y la violencia creciente. Chiapas fue sin duda el estado donde esto se expresó con más fuerza.

La aparición del EZLN se dio en este contexto. Primero fue una guerrilla que durante diez años, entre 1984 y 1994, se dedicó a construir una base social de apoyo en los asentamientos de migrantes de Los Altos de Chiapas hacia la Selva Lacandona (la región de las Cañadas de Ocosingo) (Leyva y Ascencio, 2002). El EZLN se levantó en armas y se pronunció por el derrocamiento del régimen político vigente el primero de enero de 1994. Este levantamiento no era esperado y afectó inmediatamente la transición a la democracia. Igualmente, al ser dirigida la protesta por una guerrilla armada, ha sido el reto más importante para la seguridad nacional de México en los últimos 25 años (Aguayo, 1987). ${ }^{4}$

Para las tres administraciones que han enfrentado este conflicto (Salinas de Gortari, Ernesto Zedillo y Vicente Fox), el reto de largo plazo ha sido resolver los problemas sociales que aún permanecen. Las condiciones políticas en el estado de Chiapas y el país son notable- 
mente distintas a las de 1994, pues ha avanzado el proceso de democratización en los ámbitos nacional y estatal. Con el cambio de gobierno, en diciembre del año 2000, Vicente Fox se concentró en tratar de convencer políticamente al Congreso que la reforma al artículo segundo de la Constitución era la solución al conflicto. Así, dicha reforma constitucional dejó fuera la principal demanda del EZLN, que ha sido el reconocimiento de los derechos colectivos y el usufructo de los recursos naturales (Diario Oficial de laFederación, 2001). Esto derivó en un rechazo del EZLN a la reforma, y éste buscó su alternativa de lucha en otros frentes. El actual gobierno de Felipe Calderón continúa omitiendo, como sus predecesores, que una de las causas principales del alzamiento es la demanda por el reconocimiento de la especificidad de lo indígena.

\section{Los dos Méxicos y el EZLN}

¿Por qué las reformas jurídicas no son suficientes? La respuesta está en que no es creíble para el EZLN que esta reforma jurídica tenga capacidad de resolver los problemas estructurales que dieron origen a la rebelión. Ello es porque en cuestiones económicas, políticas, sociales, jurídicas y culturales, existen dos Méxicos. Hay un México urbano y desarrollado del centro al norte del país. Hay otro México rural ubicado básicamente en el sur. Igualmente, en Chiapas existe el mismo dualismo: el de las ciudades y la costa - el sector moderno - yelde los Altos y la Selva — el marginado, excluido e indígena-

En el México del sur la ley no se aplica. Es letra muerta. Por ello, las reformas jurídicas no son escuchadas por el EZLN, pues el gobierno no tiene capacidad para aplicar la ley en el México rural y marginado. ElEZLN se alzó en 1994 intentando representar a la población indígena y al México pobre y excluido. En el país urbano y moderno se está construyendo un sistema político de democracia formal-electoral, que no beneficia a los indígenas y marginados en su condición de vida. En otras palabras, en el México pobre, no se cree en la economía de libre mercado y tampoco se confía en la democracia formal electoral. Así, el discurso "militarista" del EZLN continúa vigente pues se dirige al México marginado, a pesar de que hay un cese al fuego desde hace trece años.

Al continuar 'levantado' contra el gobierno, en 2007, es necesario analizar las mutaciones ideológicas y políticas que el EZLN ha mostrado en su vida como organización. Su fecha de nacimiento fue en 1984. Hay tres períodos en su vida política. El primero, de 1984 a 1994, caracterizado por la acumulación de fuerzas sociales y políticas entre los indígenas de las Cañadas de Ocosingo (selva del estado de Chiapas), y de autoorganización que planificaba construir un ejército guerrillero capaz de enfrentar al gobierno (Jan de Vos, 2000). Es claro que el EZLN tuvo un origen de 'guerrilla clásica', marxista-leninista-maoísta, moviéndose en la casi total clandestinidad.

El segundo período se da a partir de 1994. Se transforma notablemente su plataforma ideológica, producto del 'éxito' político y las simpatías en numerosos sectores de la sociedad mexicana e incluso en el exterior. El éxito se debió a que su capital humano fue de indígenas. Igualmente, logró conformarse como la primera guerra de guerrillas en Internet (Ronfeldt, 1998: 181).

Este período que va de 1994 a los primeros meses de 2001 tuvo como eje central la lucha por lo indígena. Terminó con la 'caravana zapatista' o 'marcha del color de la tierra' de 1,lll representantes indígenas y con la presencia de los comandantes del EZLN en el Congreso, el 28 de marzo de 2001. Posteriormente, fue aprobada por el Senado, el 25 de abril, la Ley de Derechos y Cultura Indígena; y por la Cámara de Diputados, el 28 de abril del mismo año. La ley fuecalificada por elEZLN como una burla legislativa por no apegarse a los acuerdos de San Andrés Larraínzar, así como tampoco a las negociaciones con la Comisión de Concordia y Pacificación (COCOPA), instancia de negociación creada en 1994 durante el gobierno de Salinas de Gortari, conformada por representantes de los partidos en las cámaras de diputados y senadores (Sariego, 2005).

En la propuesta de la COCOPA, los pueblos indígenas eran vistos como sujetos colectivos de derecho a través de un régimen de autonomía. Como consecuencia, se 
reconocía una serie de derechos políticos, económicos, de acceso e impartición de justicia, culturales y de protección a los indígenas migrantes. En materia política, las comunidades debían ser sujetos de derecho público. En materia económica, se establecía el derecho de los pueblos indígenas a acceder de manera colectiva al uso y disfrute de los recursos naturales de sus tierras y territorios. En materia de educación y medios de comunicación, se reconocía su derecho para adquirir, operar y administrar sus propios medios (Stavenhagen, 2003).

Como se observa, la propuesta de la COCOPA y la del gobierno, diferían principalmente, respecto al sujeto titular de los derechos colectivos, específicamente el de la libre determinación, el acceso al uso y disfrute de los recursos naturales, el derecho de los pueblos indígenas al acceso y operación de medios de comunicación, el derecho al desarrollo y el acceso a la riqueza nacional. ${ }^{5} \mathrm{El}$ gobierno nunca ha reconocido estos derechos y dirigió sus propuestas jurídicas a los derechos individuales.

El tercer período dio inicio en el 2001. Las negociaciones se congelaron durante todo el período de gobierno del presidente Vicente Fox. Hubo una recomposición ideológica y política en el EZLN, en la que no se aceptó la legitimidad del gobierno ni se reconoció la democracia. También se dio la ruptura con la izquierda "institucional", representada por el PRD. El EZLN, a partir de 2003, desarrolló varias estrategias políticas alternativas, entre ellas, las 'Juntas de Buen Gobierno'. ${ }^{6}$ El propósito fue buscar autonomía de facto con relación a los gobiernos federal, estatal y municipal. Así, el EZLN rechazó la democracia existente, por ser sólo para el México desarrollado y no para el país de los marginados y excluidos.

\section{Más allá del EZLN: el atraso del campo contra la democracia}

La gobernabilidad en las zonas rurales de México ha sido el elemento más débil de las estructuras del sistema político mexicano. Es donde se han presentado las más notables fracturas y disidencias. Del campo provienen las debilidades más profundas respecto a la democracia. En México, la reforma agraria durante muchas décadas fue el instrumento estatal por excelencia para regular conflictos. Sin embargo, la crisis aguda en que se encuentra el campo mexicano ha empezado a repercutir en un resquebrajamiento de las estructuras políticas rurales tradicionales y autoritarias. También han surgido organizaciones sociales que han buscado abrir el diálogo con el Estado sin los intermediarios tradicionales del régimen del pasado, gobernado por el Partido Revolucionario Institucional (PRI).

El EZLN es una organización que no desea institucionalizarse. En los años posteriores a la Revolución Mexicana (1920-1950), la política del Estado era asimilacionista e integracionista respecto a la población indígena. La Confederación Nacional Campesina (CNC) y el Instituto Nacional Indigenista (INI) fueron los órganos que sirvieron para implementar esta política y establecer una relación autoritaria. En 1975, amplios grupos de campesinos-indígenas rompieron con la CNC y demandaron el reconocimiento de su especificidad cultural.

En Chiapas, la reforma agraria fue incompleta y benefició a los grandes propietarios. A partir de los setenta y, gradualmente, hasta los ochenta se llevó a cabo la toma de tierras por parte de los campesinos indígenas tsotsiles, tseltales y tojolabales (Ruiz y Burguete, 1998). A esto se le llamó un nuevo movimiento indígena que además de reivindicaciones por la tierra comenzó a exigir derechos políticos, coincidiendo con los planteamientos que después haría el EZLN (Collier, 2001). Los grandes propietarios crearon estructuras paramilitares, llamadas "guardias blancas", que contribuyeron a una gran polarización y enfrentamiento, apoyadas principalmente por el gobierno estatal. Así surgió el EZLN (Harvey, 1995; Benjamin, 1995).

En los noventa, a este conflicto por la tierra se agregaron dos problemas no resueltos. El primero, fue el tema de los derechos indígenas y la reforma constitucional (López Barcena, 2001). Esta problemática también se ha debatido en otros estados del país con amplia densidad de pobla- 
ción indígena, aunque la conflictividad política en aquellos no tiene el mismo nivel que en Chiapas (Bailón, 2004). El segundo problema no resuelto ha sido el ambiental, que tiene que ver con la forma de explotación de los recursos naturales, su creciente escasez y la lucha por ellos. ${ }^{7}$

Las condiciones de pobreza, marginación y exclusión de la población indígena en Chiapas eran similares, en 1994, a las del momento del surgimiento de los movimientos insurreccionales a principios de los años ochenta en países como Guatemala y El Salvador. En el nivel político, los representantes locales del sistema político mexicano regulaban los conflictos corporativamente y cuando no era posible la cooptación se recurría a la fuerza pública, guardias blancas y fuerza militar para contener las protestas campesinas e indígenas. En Chiapas, lo común era la violación sistemática de los derechos humanos.

Así, coincidió en el tiempo una crisis agraria con un colapso político determinado por la inviabilidad del modelo de control priista prevaleciente, basado en la defensa de los grandes agricultores. Aparecieron las agrupaciones campesinas e indígenas autónomas, la teología de la liberación cobró fuerza, como, posteriormente lo haría el EZLN. Esta situación también coincidió con una explosión demográfica y la correspondiente migración incontrolada de los Altos a la Selva Lacandona en busca de tierra. La fragilidad de la Selva Lacandona para actividades agropecuarias, la convirtió en un ecosistema no sustentable. La implementación de las reformas 'neoliberales' a la agricultura en los noventa, además de la apertura de mercados, provocó, entre otros efectos, una gran depresión de la economía cafetalera.

En este escenario, el EZLN fue el líder y el catalizador del descontento de los movimientos sociales de protesta acumulados en Chiapas. La presencia indígena en el EZLN orientó el rumbo de las negociaciones con los voceros del gobierno, la sociedad civil y la comunidad internacional. El tema principal fue, entre 1994 y el año 2000, la defensa de los derechos indígenas. ${ }^{8}$ Lo anterior muestra que Chiapas se convirtió en un eslabón débil para la transición a la democracia mexicana.

\section{La estrategia del gobierno y el paramilitarismo}

Para enfrentar al EZLN, la estrategia del gobierno federal mexicano se orientó en siete vertientes: 1) responder a las demandas sociales, en particular, las de los municipios con mayor índice de marginación y pobreza; 2) promover la inversión privada para impulsar la economía de Chiapas; 3) reafirmación y vigencia del estado de derecho; 4) concertación política inter e intracomunitaria; 5) ayuda humanitaria para la población desplazada de sus comunidades; 6) apoyo a la legislación sobre los pueblos y comunidades indígenas; y 7) alcanzar una solución política y pacífica al conflicto con el EZLN (Secretaría de Gobernación, octubre, 2000). Desde el inició del conflicto en 1994, el gobierno comenzó a gastar grandes cantidades de dinero para programas sociales, intentando quitar "el agua al pez"; en otras palabras, quitar al EZLN el apoyo de la población. A la vez, se fueron constituyendo las estructuras de diálogo, mediación y negociación, que condujeron a los Acuerdos de San Andrés Larráinzar.

Como se puede observar, el gobierno federal se propuso enfrentar el conflicto en Chiapas atendiendo tanto las causas estructurales como la negociación política. Estos siete puntos sólo estuvieron en el discurso, pues entre 1994 y 1998 el gobierno recurrió a los grupos paramilitares para enfrentar comunidades zapatistas, así como a una militarización y ocupación territorial con fuerzas del ejército. La aparición de los grupos paramilitares creó una gran tensión política que destruyó la posibilidad de la negociación. Esto deterioró la imagen de la estrategia oficial, la que para contener al zapatismo utilizó formas que incluían violaciones a los derechos humanos.

Así, el EZLN encontró las justificaciones para no negociar. El argumento fue que en realidad el gobierno hacía una "guerra sucia". Para el EZLN, la negociación era falsa. Para el gobierno, había que hacer un doble track: hacia la opinión pública, negociación y solución estructural; hacia las comunidades indígenas, represión, paramilitarismo y guerra sucia. Esto distorsionó notablemente el proceso de transición hacia la democracia 
entre 1994 y el 2000. En este sentido, la contrainsurgencia en Chiapas fue similar a la implementada en muchas partes del mundo: programas sociales, con militarización y hasta paramilitarización.

\section{Chiapas y la seguridad nacional}

Con el cambio de gobierno en el año 2000, el gobierno de Fox buscó una distensión rápida a través de un retiro parcial de las tropas. A la par, se concretó la aprobación de la leyindígena, que incluyó los aspectos menos controversiales de los Acuerdos de San Andrés Larráinzar. Sin embargo, la ley de 2001 no fue producto de una negociación, sino fue un acto unilateral del gobierno. El EZLNimpulsó la caravana zapatista (enero-abril de 2001) como acción alternativa. Así, la ausencia de diálogo y la falta de concertación entre las partes fue la característica a partir de 2001 .

Sin embargo, el retiro parcial del ejército en las zonas de conflicto y la desactivación de los grupos paramilitares beneficiaron la distensión. ${ }^{9}$ Esto se vio en el nivel de gobernabilidad del estado. En Chiapas, ningún gobernador había concluido su período de gobierno durante los últimos 50 años del siglo XX. El gobernador de Chiapas Pablo Salazar, quien asumió el poder en el año 2000, fue el primer gobernador en concluir su gobierno, a la vez que se alejó de los grupos tradicionales de poder, los grandes propietarios. El EZLN, en la práctica, se alejó de la confrontación, y se redirigió a construir un "poder local alternativo". Esto se logró a partir de 2003 con la instauración de los municipios autónomos llamados "Los Caracoles". Es decir, el repliegue y silencio del EZLN se orientaron a restablecer el tejido social y político quebrantado en las comunidades, base de apoyo del EZLN. A ello contribuyó el gobierno, dejando libre el espacio político, también sin confrontación directa.

\section{Los Caracoles y la democracia del México marginado}

Los Caracoles fueron inaugurados simbólicamente en Oventik, el 9 de agosto de 2003, y de acuerdo con el subcomandante Marcos "representa un esfuerzo organizativo de las comunidades, no sólo para enfrentar los problemas de la autonomía, también para construir un puente más directo entre ellas y el mundo" (subcomandante Marcos, julio 2003). Para Pablo González Casanova (2003), el esfuerzo va más allá al tratarse de "zonas de solidaridad entre localidades y comunidades afines en redes de gobiernos municipales autónomos, que a su vez se articulan en redes de gobierno que abarcan zonas y regiones más amplias. En cada uno de Los Caracoles hay una 'Junta de Buen Gobierno' formada por uno o dos delegados de los Consejos Autónomos que existen en cada Caracol; su función exclusiva es la impartición de justicia; la salud comunitaria; la educación, la vivienda, la tierra, el trabajo, la alimentación, el comercio, la información y la cultura, el tránsito local.

El derecho a las autonomías fue reivindicado desde la Tercera Declaración de la Selva Lacandona, de junio de 1994, y establecido en los Acuerdos de San Andrés Larráinzar firmados el 16 de febrero de 1996. Este tema no fue incluido en la Ley de Derechos y Cultura Indígena, firmado por el Senado de la República el 25 de abril de 2001. En otras palabras, cada cual, gobierno y EZLN, caminaron en direcciones diferentes sin confrontación directa.

\section{Éxitos y yerros políticos del EZLN en sus 13 años de trayectoria}

Es difícil sostener que el alzamiento del EZLN en 1994 fue negativo para la transición a la democracia. Por el contrario, introdujo dos temas en el debate, el de la pobreza y el de los indígenas, que es muy importante tenerlos en cuenta en países con dualismo estructural como México. En otras palabras, debido a que hay dos Méxicos, el alzamiento puso en duda lo limitado de sólo concebir la democracia como cambio de gobierno a través de elecciones.

El rechazo la democracia liberal-electoral, por parte del EZLN, se volvió un caso raro de no acoplamiento a la institucionalidad. Es decir, es una guerrilla que no ha realizado acciones militares, pero que tampoco ha 
buscado insertarse en la legalidad. Con esta posición, no ha provocado crisis de gobernabilidad. El EZLN y el alzamiento indígena dejaron de ser un problema de seguridad nacional. Sin embargo, en el proceso de transición a la democracia en México, queda pendiente cómo van a participar las comunidades indígenas y sus liderazgos. En este difícil camino, no participar en la democracia es una variable que opera a favor del creciente aislamiento del EZLN. Así, se observa un contradictorio balance de éxitos y fracasos.

1) El intento de constitución del Frente Zapatista de Liberación Nacional a fines de los noventa no tuvo eco en las ciudades. Ha sido muy difícil la relación de dicho frente con la sociedad civil.

2) La Marcha del Color de la Tierra, de 2001, o Caravana Zapatista a la ciudad de México, tuvo un gran impacto nacional. Logró que el gobierno de Vicente Fox reformara la Constitución Política con la finalidad de reconocer en ella los derechos de los pueblos indígenas. Sin embargo, la reforma no tuvo concordancia con la propuesta de la COCOPA. El EZLN quedó insatisfecho y se replegó.

3) Hay un conflicto abierto entre el EZLN y el Partido de la Revolución Democrática (PRD). De ser relaciones muy cercanas en el período 1994-1997, se ha observado una separación gradual. El PRD, en las campañas electorales de 2000 y 2006, no colocó el tema indígena como un asunto prioritario en la nueva relación entre los pueblos indígenas y el Estado. Además, durante las discusiones en las cámaras de diputados y senadores, el PRD no defendió los Acuerdos de San Andrés en su versión original. La evolución del discurso antiglobalizador y antisistema del EZLN no ha ayudado en la relación con el PRD, pues el planteamiento político de éste está dentro de los márgenes institucionales.

4) También hay un alejamiento con un sector de la Iglesia aquel relacionado con la Teología de la Liberación. La Iglesia y el EZLN han tenido estrategias diferentes para ubicar el tema indígena en la agenda nacional.
Esto se observó en la relación entre la Comisión Nacional de Intermediación (CONAI) y el EZLN. La CONAI fue encabezada desde 1994 por el obispo emérito de San Cristóbal de Las Casas Samuel Ruiz, con el propósito de ser la instancia mediadora que buscara alcanzar la paz (CONAI, 1998). Los esfuerzos de mediación de la CONAI estuvieron orientados a lograr que las partes negociaran la paz. La CONAI no logró sus objetivos debido a que las estrategias y fines del gobierno y del EZLN no encontraron convergencias. El EZLN tuvo una estrategia "prolongada", en la que no importaba la paz inmediata, sino la paz sustantiva, en la que se obtuvieran sus demandas sin ceder a lo acordado con la COCOPA. El discurso de mediación de la CONAI fue más cercano a los propósitos de lograr justicia local y comunitaria (lucha contra los cacicazgos y la represión), y menos vinculada al discurso del EZLN referido a la anti globalización y a la confrontación, de forma abierta, con el sistema.

5) Se observa una "desilusión" y "desencanto" hacia toda la elite política nacional por parte del EZLN. Se rechaza "el poder". Esto aleja la posibilidad de diálogo y negociación con el gobierno.

6) En el año 2001, el regreso del EZLN a la selva Lacandona después de la Marcha del Color de la Tierra planteó algunas interrogantes. ¿Qué explica el repliegue estratégico? ¿Fue tarea cumplida mostrar su fuerza política, asistir al Congreso y expresar sus planteamientos sobre el contenido de la ley?

7) A partir de 2001, se observa un viraje e introspección estratégica y existencial. El EZLN se dedica a construir la "alternativa" de Los Caracoles y las Juntas de Buen Gobierno con sus bases de apoyo comunitarias. Hacia el exterior, se buscan los nexos con las redes de organizaciones antiglobalización, tanto en México como el mundo.

De esta manera, se perfilan dos proyectos en el EZLN: uno local, con fuerte arraigo, visión indígena y constructivista, en los asentamientos de migrantes campesinos- 
indígenas desarraigados y abandonados por el Estado. El segundo proyecto se orienta a fortalecer la relación con los movimientos contestatarios antiglobalizadores. Es un desafío para el EZLN hacer oscilar su acción entre ambos proyectos. La estrategia de "La Otra Campaña", en 2006, tuvo menos apoyo social y político del esperado por la dirigencia del EZLN y provocó un conflicto abierto con el PRD. El EZLN no apoyó la campaña electoral de Andrés Manuel López Obrador.

Todos los elementos anteriores han sido los principales obstáculos para la negociación. La distancia que existe entre los planteamientos del EZLN y los del Estado es cada vez más grande. El esfuerzo local, de Los Caracoles y las Juntas de Buen Gobierno, no implica necesariamente confrontación con el Estado, pero sí con algunas fuerzas locales en Chiapas, como los grandes propietarios y las autoridades políticas "institucionales", principalmente municipales.

\section{Reflexión final: ¿y la democracia?}

Después de 13 años de conflicto abierto entre el EZLN y el gobierno, las condiciones políticas en Chiapas son notablemente distintas. Comparando 1994 con el año 2007, hay mayor estabilidad política, se han casi desmantelado los grupos paramilitares. La existencia de Los Caracoles y de las Juntas de Buen Gobierno es muestra de condiciones más favorables para el desarrollo de opciones políticas nuevas. En cualquier escenario de posible negociación futura entre el gobierno y el EZLN, se necesita tomar en cuenta la participación activa y las demandas de múltiples de las organizaciones de la sociedad civil.

Existen defacto muchas formas autónomas de organización política y social en las comunidades indígenas. La implementación de programas y proyectos de carácter social y económico por parte del Estado, orientados a impulsar el desarrollo de las regiones, sobre todo donde se encuentran los indígenas, requiere considerar ineludiblemente el diálogo y la negociación desde el ámbito comunitario con las organizaciones. Esto significa que el EZLN podría negociar en el ámbito local, aunque no lo haga en el nacional.

La Ley de Derechos y Cultura Indígena de 2001 no incorpora en su totalidad las aspiraciones de los pueblos indígenas de México. Por eso sigue pendiente en la reforma del Estado el tema indígena. En los debates tanto en México como en América Latina entre los movimientos indígenas y los gobiernos se está discutiendo la consideración de las autonomías, los derechos al territorio y el usufructo de los recursos naturales.

En el caso de las negociaciones entre el EZLN y el gobierno mexicano, éstas están en un punto muerto. Como en la mayoría de los países en América Latina, en México, una de las debilidades del proceso de transición a la democracia es la dificultad que tiene el Estado para negociar con movimientos de protesta de nuevo tipo, antisistémicos y en ocasiones violentos. Estos movimientos contestatarios tampoco buscan las vías político-institucionales, y tienen gran debilidad para sostenerse, para tener respaldo en la sociedad y permanencia en el tiempo. Esto sucede sobre todo con algunos movimientos sociales y políticos críticos que provienen de diversos sectores que no encuentran los espacios de diálogo y participación en las estructuras del Estado. De esa manera, radicalizan sus formas de lucha.

El punto de conflicto se da por las condiciones de marginalidad, exclusión social y política que los lleva a expresiones confrontativas y radicales. De igual manera, se da incapacidad en todos los niveles del Estado (federal, estatal y municipal), de poder atender sus demandas, escuchar o negociar con dichos movimientos y dialogar e interactuar con sus líderes. Este es el caso de las conflictivas relaciones entre el EZLN y el Estado mexicano, apoyado por amplias estructuras de poder. El EZLN fue el catalizador (1994-2001) y articulador de algunas de las expresiones de descontento más importantes que provinieron del México rural e indígena, en este caso en Chiapas. En esos años su impacto fue a nivel nacional.

Por su parte, el Estado mexicano no ha podido construir mecanismos legales o políticos para relacionarse 
con los movimientos sociales emergentes. El peligro para la democracia es que estos movimientos, al igual que en muchos países de América Latina, cada vez tienen expresiones más radicales. Es decir, que esta debilidad de la actual democracia mexicana explica el por qué las negociaciones de paz entre el EZLN y el gobierno están en punto muerto o congeladas. El gobierno de Felipe Calderón no tiene ninguna propuesta concreta para intentar resolver la confrontación con el EZLN, debido a que el tema indígena se fue enfriando durante el gobierno de Vicente Fox (Hernández, Paz y Sierra, 2004). Para el actual gobierno, el tema indígena se reduce sólo a políticas de combate a la pobreza. Por su parte, el EZLN se propone 'dirigir' los movimientos sociales contestatarios alejando las posibilidades de negociación con el gobierno. En otras palabras, no hay puntos de convergencia entre las partes para intentar regresar a la mesa de negociación. En síntesis, tanto desde el gobierno como desde el EZLN, la actitud no negociadora es negativa para la democratización de México.

\section{Notas}

${ }^{1}$ Estimaciones de la población indígena, a partir de la base de datos del XII Censo general de población y vivienda 2000, INEGI.

2 Se hicieron cambios a la Constitución vinculados a la temática indígena, en los artículos $4^{\circ}$ y $27^{\circ}$, en 1992. El primero se refiere al reconocimiento de la composición pluricultural que tiene México, sustentada en sus pueblos indígenas y que la ley protegerá y promoverá el desarrollo de sus lenguas, culturas, usos y costumbres, recursos y formas específicas de organización social, garantizando su acceso efectivo a la jurisdicción del Estado. Constitución Política de los Estados Unidos Mexicanos. Actualizada con la reforma publicada el 7 de abril de 2006, http://www.ordenjuridico.gob.mx/.

${ }^{3}$ De acuerdo con el censo del año 2000, en México existen 6.7 millones de personas hablantes de lengua indígena, sobre un total de 98 millones de habitantes.
${ }^{4}$ En los años ochenta había análisis que señalaban la explosiva situación que se vivía en Chiapas, producto de condiciones muy contrastantes en lo social, y del aumento de los enfrentamientos entre los propietarios de latifundios y las poblaciones campesinas e indígenas reclamando tierras, a la par de la existencia de los conflictos en Centroamérica y la presencia de los refugiados guatemaltecos en México.

${ }^{5}$ Para más detalles de las divergencias entre la propuesta de la COCOPA y el gobierno ver Francisco López Bárcenas, Legislación y Derechos Indígenas en México.

${ }^{6}$ Las Abejas son comunidades aliadas a los zapatistas que trataron de buscar alternativas productivas y organizativas, que fueron muy golpeadas por los grupos paramilitares en 1997 para evitar que se irradiara su ejemplo.

${ }^{7}$ Este problema es común a muchos países en los que habitan poblaciones indígenas en regiones con recursos limitados. En el caso de Chiapas es gravísimo el deterioro de la selva Lacandona, pues el ritmo de deforestación es de $1.6 \%$ anual, lo que llevaría a que en el año 2001 sólo se conservaría $10 \%$ de las especies de flora y fauna que habitan en la región. "Consenso en estrategia para salvar Lacandona”, Reforma, 27 de junio de 2003: 2-A.

${ }^{8}$ No es sino hasta la Tercera Declaración de la Selva Lacandona de enero de 1995 cuando el tema indígena se vuelve central en el discurso zapatista señalando que "La cuestión indígena no tendrá solución si no hay una transformación RADICAL del pacto nacional".

9 Tanto el gobierno federal como el estatal, encabezado por Pablo Salazar, empezaron a enjuiciar a los dirigentes de los grupos paramilitares, principalmente a los que habían cometido la masacre de Acteal, en la que murieron asesinados 45 indígenas, en diciembre de 1997.

\section{Bibliografía}

Aguayo, Quezada Sergio, 1987, “Chiapas: las amenazas a la seguridad nacional”, en serie Estudios del Centro Latinoamericano de Estudios Estratégicos, EST-006-86, junio, México. 
—, 2007, El Almanaque Mexicano 2007, ediciones Aguilar, México.

Álvarez, H. Luis, 2003, "Chiapas: dilemas actuales del conflicto y la negociación”, en Arnson, Cyntia, Raúl Benítez, Manaut y Andrew Selee (editores), Chiapas: interpretaciones sobre la negociación y la paz, UNAM, Centro de Investigaciones Sobre América del norte y Woodrow International Center for Scholars, México.

Bailón, Jaime Moisés, 2004, "Los derechos indígenas en México después de las reformas de 2001: una mirada hacia atrás y otra hacia adelante", en Memorias de la Jornada Interactiva sobre "La reforma constitucional en materia indígena: balance y perspectivas", El Colegio de México, A. C., junio, México.

Bailón, Moisés Jaime, (compilador), 2003, Derechos humanos y derechos indígenas en el orden jurídico federal mexicano, Comisión Nacional de Derechos Humanos, México.

Carrasco, Tania y Augusta Molnar, 2001, "Indigenous Peoples and Poverty", en Ciugale, M. Marcelo, Oliver Lafourcade y Ving H. Nguyen (editores), México. A Comprehensive Development Agenda for the New Era, The World Bank, Washintong D. C.

Collier, George, 2001, "El nuevo movimiento indígena", en De León Pasquel, Lourdes (coordinadora), Costumbres, leyes y movimiento indio en Oaxaca y Chiapas, CIESAS, Miguel Ángel Porrúa, México.

CONAI. Comisión Nacional de Intermediación, 1998, Archivo Histórico enero de 1994-julio de 1998, CD, Edición de Servicios y Asesoría para la Paz A. C., México.

De Vos, Jan, 2000, "Raíces históricas de la crisis chiapaneca”, en Arnson, Cyntia, Raúl Benítez, Manaut y Andrew Selee (editores), Chiapas: interpretaciones sobre la negociación y la paz, UNAM, Centro de Investigaciones Sobre América del norte y Woodrow International Center for Scholars, México, pp. 36-40.

Diario Oficial de la Federación, 2001, "Transitoriedad de las reformas constitucionales en materia indígena de 2001", México.
Global Exchange, 2000, Siempre cerca, siempre lejos. Las fuerzas armadas en México, Centro Nacional de Comunicación Social, A. C., México.

González Casanova, Pablo, 2003, "Los caracoles zapatistas. Redes de resistencia y autonomía”, en Memoria, núm. 177, CEMOS, noviembre, México.

González, Casanova Pablo, 2003, "Los caracoles zapatistas. Redes de resistencia y autonomía”, Memoria, núm. 177, CEMOS, México.

Harvey, Neil, 1995, "Rebelión en Chiapas: reformas rurales, radicalismo campesino y los límites del salinismo", en Viqueira, Juan Pedro y Mario Humberto Ruz (editores), Chiapas. Los rumbos de otra historia, CIESAS, UNAM, CEMCA, México, pp. 447-479.

Hernández Aída, Sarela Paz y María Teresa Sierra, 2004, (coordinadoras), El Estado y los indígenas en tiempos del PAN: neoindigenismo, legalidad e identidad, CIESAS, México.

Leyva Solano, Xochitl y Gabriel Ascencio Franco, 2002, Lacandonia al filo del agua, segunda edición, CIESAS, UNAM y FCE, México.

López Bárcenas, Francisco et al,. 2004, Los derechos indígenas y la Reforma Constitucional en México, Centro de Orientación y Asesoría a Pueblos Indígenas, A.C., México, 2001 y Varios Autores. Autonomía y derechos de los pueblos indios, Cámara de Diputados, México, 1998, Memorias de la Jornada Interactiva sobre "La reforma constitucional en materia indígena: balance y perspectivas", El Colegio de México, A.C., junio, (publicada en CD).

OIT. Organización Internacional del Trabajo, 1989, "Convenio No. 169 sobre Pueblos Indígenas y Tribales”, junio, Ginebra.

Ronfeldt, David, (editor), 1998, The Zapatista Social Netwar in México, Rand Corporation, Santa Bárbara, p.181.

Ruiz Hernández, Margarito y Araceli Burguete, 1998, "Chiapas: organización y lucha indígena al final del milenio (1974-1998)”, Asuntos Indígenas, núm. 3.

Sariego Rodríguez, Juan Luis, 2005, "Política indigenista en tiempos de alternancia: de los dichos a los hechos", 
en Aziz Nassif, Alberto y Jorge Alonso (coordinadores), El Estado Mexicano: herencias y cambios. Sociedad civil y diversidad, Volumen III, CIESAS, Miguel Ángel Porrúa, México, pp. 291-305.

Secretaría de Gobernación, 2000, Coordinación para el Diálogo y la Negociación en Chiapas, Chiapas con justicia y dignidad. Memoria, acuerdos, compromisos, acciones y obras, México, pp. 189-191.

Stavenhagen, Rodolfo, 2003, "Mexicós Unfinished Sym phony: the Zapatista Movement", en Joseph S. Tulchin y Andrew Selee (editors), Mexico's Politics and Society in Transition, Boulder, Lynne Rienner Publishers.

Subcomandante Insurgente Marcos, 2003, "Chiapas: la Treceava Estela”, http://www.nodo50.org/pchiapas/ chipas/documentos/calenda/chiapas6.html.

Tavanti, Marco, 2003, Las Abejas: Pacifist resistance and syncretic identities in a globalizing Chiapas, Routledege, New York.

Zúñiga, Nieves García-Falces, 2005, "Conflictos por recursos naturales y pueblos indígenas", en Pensamiento Propio, núm. 22, año 10, julio-diciembre. 